\title{
Bone Trabeculae
}

National Cancer Institute

\section{Source}

National Cancer Institute. Bone Trabeculae. NCI Thesaurus. Code C82999.

Anastomosing, needle-like bony structures which create a meshwork of spaces filled with bone marrow. 